\title{
Surgical Management of Supracondylar Femoral Fractures Using Retrograde Nail
}

\author{
Dr. Arun K. N ${ }^{1}$ Dr. Akshay. S. Dudhanale ${ }^{2}$ \\ Dr. Bagadia Pravin ${ }^{3}$ Dr. Nakul H.S. ${ }^{4}$ \\ Dr. Dhameliya Niravkumar $\mathrm{G}^{5}$ \\ ${ }^{I}$ Associate professor and head of unitDepartment of orthopaedics Navodaya medical college and research \\ center,Raichur-KarnatakaRajiv Gandhi University of health science,India \\ ${ }^{2,3,4,5}$ Resident doctorDepartment of orthopaedics Navodaya medical college and research center, Raichur- \\ KarnatakaRajiv Gandhi university of health science,India
}

\begin{abstract}
To evaluate the treatment and long term follow up supracondylar femoral fracture using retrograde nail

Method: Between September 2012 to January 2015, 40 distal femoral fractures on 40 patients were operated using retrograde intramedullary nail .There were 30(75\%)males and 10(25\%) were females. Age was ranging 18-75 years, with an average of 43.4 years. 26 patients were due to polytrauma.Fractures were classified according to Muller's .5\% were Type A1,15\% were Type A2,50\% were Type A3,5\% were Type C1,10\% were Type C2,15\% were Type C3.All the cases were operated with retrograde intramedullary nailing using patellar splitting approach.
\end{abstract}

Result: All fractures healed by 4 month range 3 to 5.5 months. The mean knee range of movement was 90(80 to 140). There was deep infection in 2 cases shortening more than $2 \mathrm{~cm}$ in 2 cases, valgus angulation in 2 cases, anterior knee pain in 4 cases and implant in knee joint in 2cases. there were no late mechanical failure of the implant. Neer's knee rating system was used to evaluate the function, there were $16(40 \%)$ excellent ,20(50\%) satisfactoty results,2(5\%) unsatisfactory results,2(5\%) of the cases failed. The result correlated with age of the patient and presence of an intra articular fracture.

Conclusion: The study shows distal femoral fractures were common in males due to high velocity injuries. retrograde intramedullary nailing is an excellent technique for management of distal femoral fractures since there is less soft tissue dissection. The preferred portal of entry can be reached quickly and effectively, shortens the duration of surgery decreases the need for bone grafting high union rate and good knee range movements.Complications were few which includes infection, shortening, angulation and anterior knee pain.

Keywords:Distal femoral fractures, retrograde intramedullary nailing, supracondylar nailing, Muller's classification, Neer's Knee rating system.

\section{Introduction}

The Incidence of distal femur fracture is around $37 / 100000$ patient per year ${ }^{1}$.

Despite the advances in the techniques and the improvement in surgical implant, treatment of distal femoral fractures remains challenge in many situations. It has been shown that for high velocity trauma-earlier a patient receives initial treatment better the outcome ${ }^{2}$.

The distal femur includes the distal $15 \mathrm{~cm}$ of the femur including the distal femoral metaphysis (Supracondylar) and intercondylar area $^{3}$

Supracondylar area of the femur is defined as the zone between the femoral condyles and the junction of the metaphysis with the femoral shaft.This comprises the distal $9 \mathrm{~cm}$ of the femur as measured from the articular surface. It is important to distinguish Supracondylar fractures from low diaphyseal fractures of the distal femur because the methods of treatment and prognosis are considerably different. Distal femoral fractures account for $7 \%$ of all femoral fractures, predominant in young males following high energy trauma ${ }^{3}$.

In 1970 the AO (Arbeitsgemeinschaft für Osteosynthesefragen) reported "If normal or near normal function is to be achieved, then unquestionably if correctively employed open reduction and internal fixation ensures a very high rate of success" 3 .

Muller's classification is probably the most widely accepted classification of supracondylar fractures ${ }^{3}$.

The purpose of this study was to determine the outcome of the management of supracondylar femoral fractures by the retrograde intramedullary interlocking nail. 


\section{Material And Methods}

The present study includes treatment of 40 distal femoral fractures in 40 patients by retrograde intramedullary nailing between September 2012 to September 2014.At Navodaya Medical College Hospital and Research Centre, Raichur.

\section{Inclusion And Exclusion Criteria \\ 1.1 Inclusion criteria}

- Patient with distal femur fractures.

\subsection{Exclusion criteria:}

- Patients managed conservatively

- Associated with vascular injury that requires amputation

- Fractures with epiphysieal plate open

- Pathological fractures

- Patients lost in follow up

- Open fracture type 2 and 3

After admission of patient, a careful history was elicited from the patient and or attendants to reveal mechanism of injury and the severity of trauma the patientwere then assessed clinically toevaluate their general condition and the local injury.

In general condition of the patient, the vital signs were recorded .Methodological examination was done to rule out fracture another sites.

Palpation reveal abnormal mobility,crepitus and shortening of the affected limb. Distal vascularity was assessed by dorsalis pedis and posterior tibial arterial pulsations and capillary refilling.

Radiograph of the knee with the distal half of the femur AP, lateral, right and left oblique views were obtained, pelvis with both hips AP view and tibia fullength AP and lateral to rule out other fractures.The limb was then immobilized in Thomas splint.

The patient was then taken up for surgery after investigations and making patient medically fitness for surgery .The investigation done were,

- Hemoglobin percentage, Packed cell volume(PCV)

- Complete blood count, erythrocyte sedimentation rate,bleedingtime,clotting time ,prothrombin time

- HIV ,HBsAG

- Random blood sugar, bloodurea, serumcreatinine, serum uric acid blood grouping and cross matching.

- Urine for macroscopy, sugar, albumin and microscopy

- $2 \mathrm{D}$ echo if patients age is $>60 \mathrm{yr}$

Instruments And Implants Used In Retrograde Intramedullary Nailing Of Distal Femoral Fractures

1) Supracondylar nail of varying length and diameter .Available in diameter of 10,11,12mm and length of 15, $20,25 \mathrm{~cm}$.

2) Introducer /target device

3) Template

4) Guide sleeve

5) Awl

6) Spanner hex 17

7) Guide sleeve for Kirshner wire

8) Tissue protector

9) Small extraction shaft

10) Drill guide sleeve $4.00 \mathrm{~mm}$

11) Kirshner wire, $1.8 \times 310 \mathrm{~mm}$

12) Screw driver,hex $5 \mathrm{~mm}$

13) Depth gauge

14) Cone drill, $11 \mathrm{~mm}$

15) General instruments like retractors and reduction clamps 


\section{Pre-Operative Planning}

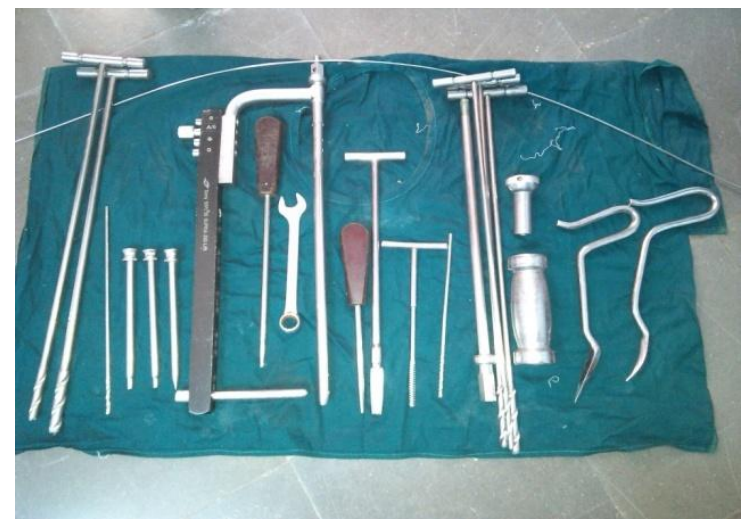

\section{Instruments}

- Appropriate length of the nail to be used was assessed clinically and radio graphically

- Preparation of the required part (Window shaving) was done prior to the surgery

\section{Operative Procedure Type Of Anesthesia}

General anesthesia was given in 14 cases and spinal anesthesia was given in remaining 26.

\section{Position}

Some of the patient were positioned on the traction table in the supineposition with the hip at an angle of approximately 15 degrees and the knee at an angel of 40-90 degrees flexion and some were positioned supine on a radiolucent table, the extremities draped free.

\section{Reduction}

The reduction of fracture fragment was done by closed method in extra-articular fractures and by open method intra articular fractures.

\section{Incision}

We have used an anterior midline vertical skin incision from the inferior pole of the patella to the tibial tuberosity.The patellar tendon was split centrally and retracted to gain access to the intercondylar notch.Selflocking retractors were used.

\section{Entry Portal}

Using imageintensifier the portal of entry was made use in two part curved awl in the inter-condylar notch. $1 \mathrm{~cm}$ anterior to the posterior cruciate ligament and checked using an image intensifier, both AP and lateral views to confirm the central position of the nail. The bone entry point was opened to a minimum diameter of $14 \mathrm{~mm}$ for the first $3 \mathrm{~cm}$.

In Type $\mathrm{C}$ fractures open reduction and fixation of the condyles with thick $\mathrm{K}-$ Wire placed anterior or posterior to the path of the nail was done.

\section{Reaming}

$3 \mathrm{~mm}$ thick long guide wire with the ball tipped stopper which is precurvedbeyond this ball (olive) was passed from the intercondylarfemoral entry point through the condyles and the fractures site, while confirming the central positioning of the tip in the trochanteric region .Reaming was performed in $0.5 \mathrm{~mm}$ steps up to 12 $\mathrm{mm}$ from $8 \mathrm{~mm}$ onwards

\section{Nail Insertion}

The nail that was selected was fit into the introducer/target device and was pushed in by hand and the position was verified by the use of image intensifier to confirm that the tip of the nail lies centrally the distal third of the femur and the distal part is $2 \mathrm{~mm}$ below the articular surface.

\section{Distal Locking}

This was done using a target device .The cortex was drilled with a $4 \mathrm{~mm}$ drill and $5 \mathrm{~mm}$ self-tapping screws were inserted of the correct length. Distal locking was done with two screws and checked under image intensifier. 


\section{Proximal Locking}

This was done by freehand technique with 2 stab incision on the lateral side .the cortex was drilled with a $4 \mathrm{~mm}$ drill and $5 \mathrm{~mm}$ self-tapping screws were inserted.This was done using two screws and checked under image intensifier.

\section{Wound Closure}

The wound was closed in 2 layers with asuction drain in cases of open reduction.

\section{Immobilization}

When fracture reduction is stable, limb was immobilized in above knee cast or above knee slab.

\section{Post-Operative Care}

1) Suction drainage for 1 to 2 days was kept in cases of open fractures

2) Day 1: Mobilization of the knee started using CPM

3) Day 2: Active quadriceps and hamstring exercises and continued CPM was done

4) Day 3onwards: Patient were kept touch-down weight bearing until there were radiographic signs of callus formation .In cases of unstable fractures and osteoporotic patients the weight bearing was delayed.

5) By 6 weeks partial weight bearing was started

6) By 12 weeks full weight bearing was started

\section{Follow Up}

All the patients were followed up at about 3 weeks, 6weeks, 3 and 6 months and 1 year. The evaluation was done based on Neer's knee rating system. Pain, function range of movements was noted and the union was assessed radiologically at regular intervals. The fracture was said to be united when there was presence of periosteal callus bridging the fracture site and trabeculation extending across the fracture site

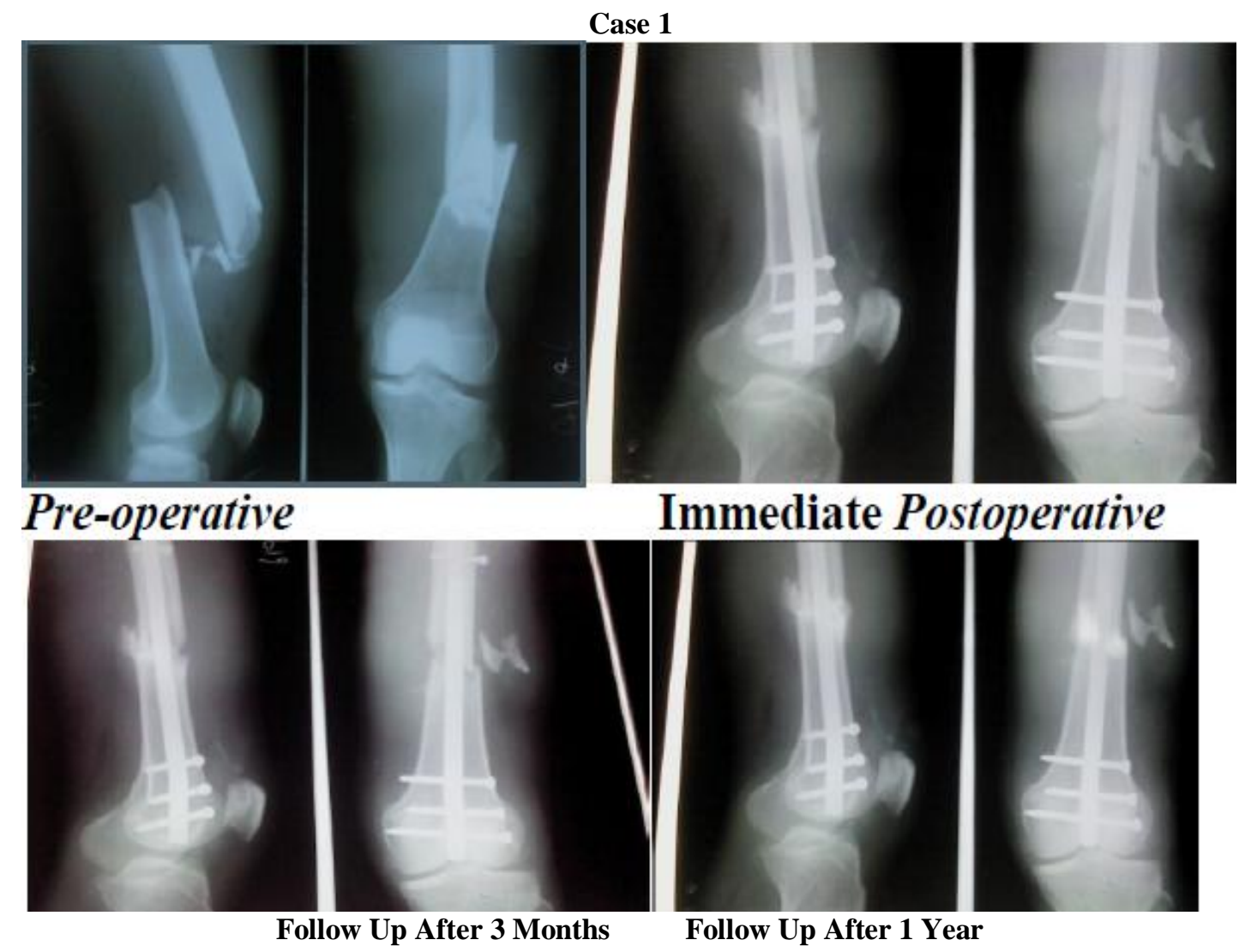




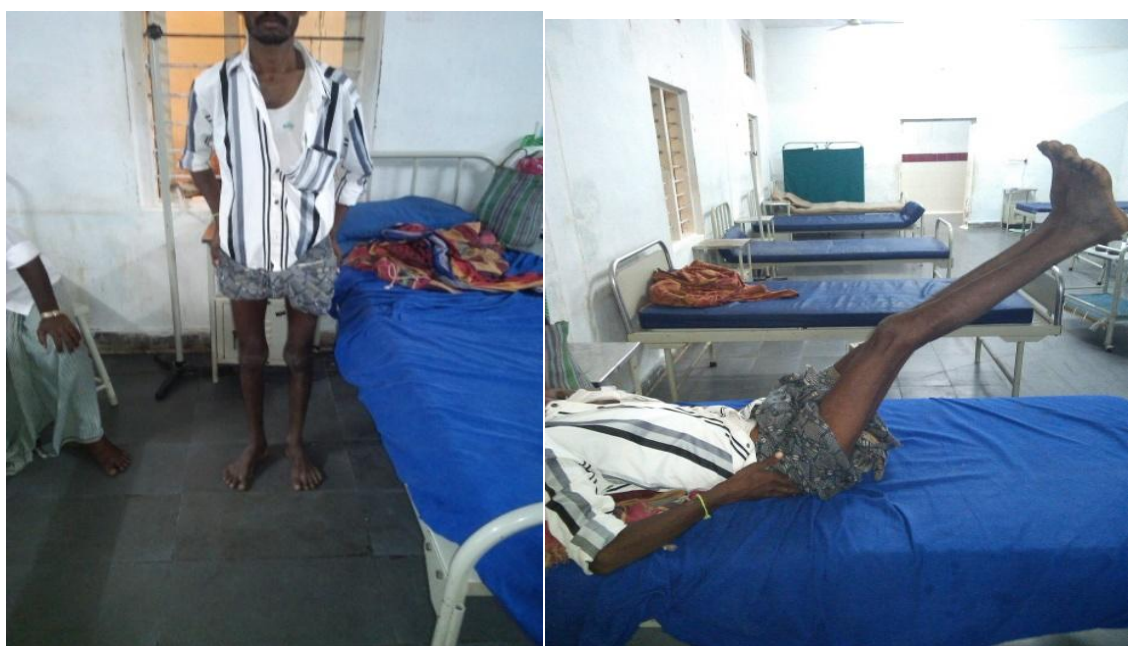

Patient Walking

Showing Knee Extension
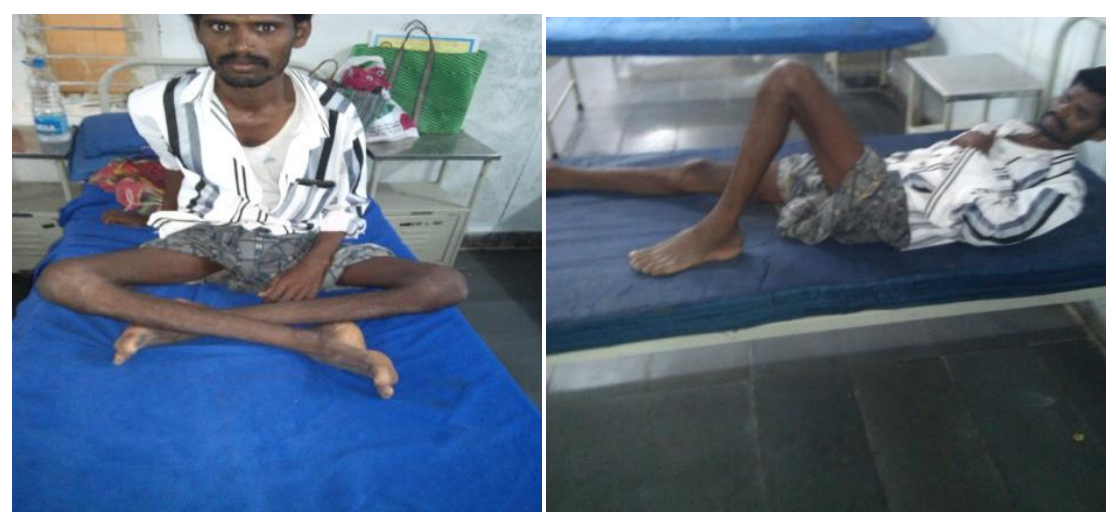

\section{Sitting Cross Leggedshowing Knee Flexion}

\section{Results}

The present study includes treatment of 40 distal femoral fractures in 40 patients by retrograde intramedullary nailing between September 2012 to September 2015.The age of these patients range from 18 to 75 years with the fracture being most common in the 30-50 years age group with an average of 46 years.Male patients were aged between 18 to 64 years with an average 40.5 years.Female patients were aged between 22 and 74 years with an average of 48 years

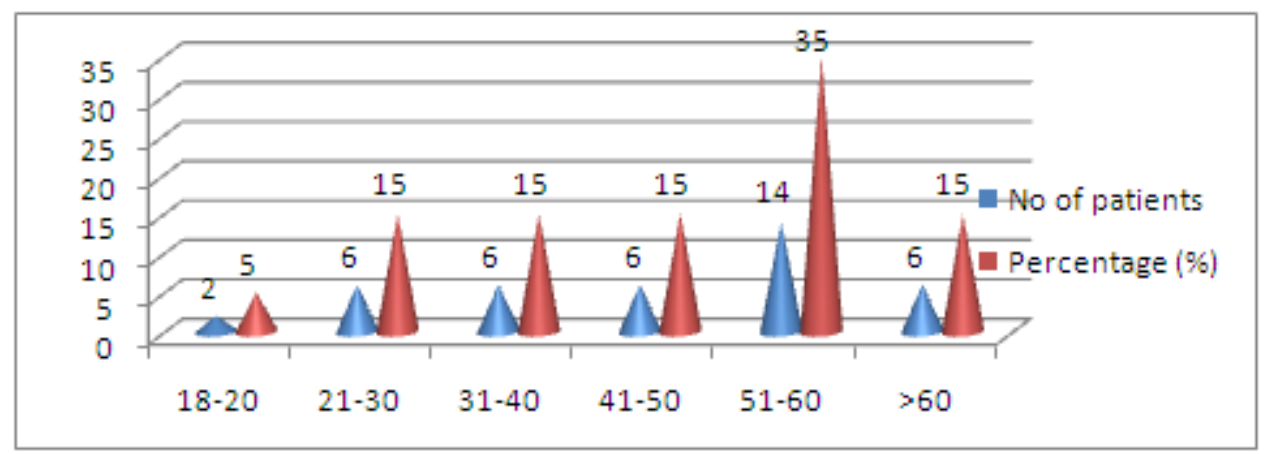

Out of 40 patients $30(75 \%)$ were male and $10(25 \%)$ were female showing male preponderance, that is probably due to male are predominately working in factories field and travelling. There were 26(65\%) with right sided and 14(35\%) with left sided distal femoral fracture.Majority of the injuries were due to road traffic accident $(75 \%)$ and 10 were due to fall (25\%)40 patients who sustained injuries, 26(65\%) of themhad polytrauma and 14(35\%) had isolated distal femoral fracture 


\section{Type Of Fracture}

Table 1.

\begin{tabular}{|l|l|l|}
\hline Type of fractures & No of patients & Percentage (\%) \\
\hline Open & 18 & 45 \\
\hline Closed & 22 & 55 \\
\hline
\end{tabular}

Open type of fracture were classified using Gustilo-Anderson classification out of the 18 fractures $4(44.45 \%)$ were type II, 6(33.33\%) were type III A , as shown in table no 2.

Table No 02

\begin{tabular}{|l|l|l|}
\hline Type of fractures & No of patients & Percentage (\%) \\
\hline Type I & 00 & 00 \\
\hline Type II & 08 & 44.44 \\
\hline Type III A & 06 & 33.33 \\
\hline Type III B & 04 & 22.22 \\
\hline Type III C & 00 & 00 \\
\hline Total & 18 & 100 \\
\hline
\end{tabular}

Out of 40 casess majority of them are type A 3 and the remaining are type A 1, A2, C1 and C3 according to muller classification.

Table No 03

\begin{tabular}{|l|l|l|}
\hline Type of fracture & No of patients & Percentage (\%) \\
\hline A1 & 02 & 05 \\
\hline A2 & 06 & 15 \\
\hline A3 & 20 & 50 \\
\hline C1 & 02 & 05 \\
\hline C2 & 04 & 10 \\
\hline C3 & 06 & 15 \\
\hline Total & 40 & 100 \\
\hline
\end{tabular}

Out of 40 patients 28 were associated with the other skeletal traumamostcommonbeingassociatedtibiafractures among them 8 tibial plateau fracture and 6 tibial shaft fracture, 2 patient had PCL injury, 2 patient had ACL injury,4 patient had distal radius fracture, 2 had patella fracture and 4 had humerus fracture. 4 patient were treated with cancellous iliac bone graft. We have used 5 holds supracondylar nail in $22(55 \%)$ cases and supracondylar recon nail in 18 (45\%) cases. Theadditionalcannulatedscrews were used outside the nail in 6 patents of type $\mathrm{C}$ for better stabilization.Out of 40 cases $6(15 \%)$ were immobilized in above knee cast, 2(5\%) was immobilized in above knee slab, 2(5\%) was immobilized in knee brace. We have not used any method of immobilization in 30(75\%). of these cases. We have measured Final range of movement according to Muller's classificationType A 1 fracture had an average range of movement Type a- $1100^{\circ}$,Type A 2 fracture had $96.6^{\circ}$,Type A3 had $102.85^{\circ}$,Type C had $120^{\circ}$,Type C2 had $95^{\circ}$ and Type $\mathrm{C} 3$ had $96.6^{\circ}$ The average time taken for union was 4 months ranging from 3 to 5.5 months. Out of total 40 cases , $2(5 \%)$ cases hold infection, $2(5 \%)$ hold a shortening of $2.5 \mathrm{~cm} .2(5 \%)$ cases had a valgus angulation of $8^{0}$ and $2(5 \%)$ had an intra-operative hypotension, anterior knee pain in 4 cases, proximal screw backing out in one cases, implant protruding to knee joint in 2cases.

\section{Results}

Out of 40 cases $16(40 \%)$ of them had an excellent result, $20(50 \%)$ hadsatisfactory result, $2(5 \%)$ had an unsatisfactory result, and $2(5 \%)$ was failure due to infection

\section{Discussion}

There has been no uniform reporting of the results of treatment of supracondylar and intracondylarfemurfractures.It is difficult to compare the result of different reported series in literature, because of difference is demographic characteristics and differing fracture characteristics and is further complicated by the use of different classification system and functional rating system.In our study the average age was 43.4 years with ranging from 17-75 years. In Moshieff.R study the average age was 55 years (21-102) Years ${ }^{4}$. In Henry the average was 48.6 years (16-101) years ${ }^{5}$.In Patterson the average age was 40 years. (21-66) years ${ }^{6}$ In our study males (70\%) were more affected than female(30\%)s. In Gellman, females $(58 \%)$ were outnumbered males $(42 \%)^{7}$ Pattern of fracture noted in Brijlal.Sseries noted about $23 \%$ of fractures asType A2, $67 \%$ as Type $\mathrm{A} 3,5 \%$ as Type $\mathrm{C} 2$ and $5 \%$ as Type $\mathrm{C} 3{ }^{9}$.Gellman series noted $12.5 \%$ of cases were Type A1, $12.5 \%$ were Type A2, 20\% were Type A3, $16 \%$ were Type C1, $12.5 \%$ were Type C2, and were $25 \%$ were Type C $3^{7}$.

In our series we had $5 \%$ as Type $\mathrm{A} 1,15 \%$ as Type $\mathrm{A} 2,50 \%$ as Type $\mathrm{A} 3,5 \%$ as Type $\mathrm{C} 1,10 \%$ as Type $\mathrm{C} 2,15 \%$ as Type C3 The mean range of movements of the knee achieved in our series was $98^{0}$ at the average 
range of movements was $80^{\circ}-140^{\circ}$ which is comparable to Henry series of study $105^{0}$ at the average of $84^{0}$ $120^{0}$ In moed $9.7 \%$ non - union ${ }^{9}$, In brijlal $19 \%$ shortening more than $2 \mathrm{cms}^{8}$. In Henry $5.6 \%$ non-union \& one cases angulation of more than $5^{07}$, in Leung -KS $8 \%$ of anterior knee pain ${ }^{10}$, Gellman et al $4.5 \%$ angulation of more than $5,25 \%$ of shortening more than $2 \mathrm{cms}^{8}$.In our study $5 \%$ infection, $5 \%$ angulation more than $5^{0}, 2$ patients had anterior knee pain, $5 \%$ of cases had shortening more than $2 \mathrm{cms}$. Proximal screw backing out in cases\& nail protruding to the knee joint in two cases.

The functional results were evaluated using Neer's criteria.Janzing et al reported about 56 cases as excellent, $33 \%$ cases as satisfactory. $11 \%$ cases as unsatisfactory and $0 \%$ failures ${ }^{11}$.In our series we had $35 \%$ cases with excellent results, $50 \%$ cases with satisfactory results, $5 \%$ with unsatisfactory results and $5 \%$ cases with failure

\section{Conclusion}

The present study was conducted to assess the functional outcome of treatment of distal femoral fractures by retrograde intramedullary nailing.Retrograde intramedullary nailing in supracondylar and intracondyalar femoral fractures makes "Biological osteosynthesis" possible in these difficult and complex fractures with less operative time, minimal soft tissue stripping minimal blood loss, decreased need for bone grafting and reasonably rigid fixation in osteoporotic bones. Post-operatively it helps in rapid mobilization and early functional rehabilitation. The significant advantage of retrograde nail is early weight bearing which cannot be recommended with platesLong term study (5 Years) are required to accurately assess the functional outcome of treatment of the distal femoral fractures with retrograde intramedullary nailing. Thus we conclude that retrograde intramedullary nailing in an excellent technique for management of distal femoral fracture including supracondylar and intercondylar fractures.

\section{References}

[1]. Hierholzer c,von Rüden C, Pötzel T, Woltmann A,Bühren V: “out come analysis of retrograde nailing and less invasive stabilization system in the distal femoral fractures, retrospective analysis". Indian journal of orthopedics 2011/May-Jun 45,(3)243 to 250 .

[2]. J.O'Brine, Robert N Meek Piotr A Blanchet. Henry M Broekhuyse,Fracture of the distal femur,

[3]. Rockwood and Green's fractures in adults5th ed(Phillidelphia: LippincottWilliams \& wilkins 2001) Volume-II, $1731-71$.

[4]. David L. Helfet, M.D. et alfractures of the distal femur,, Bruce D.browner skeletal trauma(Phillidelphia: Saunder 2002)Vol-II, 1643-83.

[5]. Mosheiff R, : "Treatment of type C supraconylar femoral fractures using a retrograde supracondylar nail., JBJS, Volume 83-B Supplement III,2001, p 290,

[6]. Henry SL, et al. Management of Supracondylar Fractures of the Femur with the GSH Supracondylar Nail: The Percutaneous Technique. Tech Orthop 1994;9:189.

[7]. Patterson, Brendan M. MD; Routt, M. L. Chip Jr., MD et al "Retrograde Nailing of Femoral Shaft Fractures". The Journal of Trauma, Injury infection \& Critical Care, Volume 38(1): Jan 1995,38-43.

[8]. Gellman, Richard E.MD; Paiement, Guy D.MD; Green, Hillary D. BA; Coughlin, R. Richard MD et al; treatment of Supracondylar Femoral Fracture with a Retrograde Intramedullary Nail”. Current orthopedic Practice. Volume 332: November 1996,90-97;

[9]. Brijlall, S.,Supracondylar femoral Nailing: Biologic fixation, The Journal of Bone and Joint Surgery. Volume 84-B Supplement I 2002,p 86;.

[10]. Moed BR, Watson JT: Retrograde intramedullary nailing, without reaming, of fractures of the femoral shaft in multiply injured patients.J Bone Joint Surg77A:1995,1520-27,

[11]. Leung-KS; Shen-WY; Mui-LT; -A: Interlocking intramedullary nailing for

[12]. Supracondylar fractures of the distal part of the femur. J -Bone-Joint-Surg-Am. 73(3): ; Mar-1991, 322-340

[13]. Janzing, Heinrich M. J.; Stockman, Bernard et al: The Retrograde Intramedullary Nail: Prospective Expirience in Patient Older than Sixty-five year. Journal of Orthopaedic Trauma. Volume 12 (5)June / July 1998, 330-33. . 